\title{
Initials Impact of Nursing Manager Perception of Empowerment and Years of Experience on Resistance to Change in Practice
}

\author{
Nadia Kiran Muhammad Afzal Muhammad Hussain Syed Amir Gilani \\ The University of Lahore, Pakistan
}

\begin{abstract}
Introduction: Nurse Managers play a vital role to maintain an organization. They are responsible for nursing employment, ward management and other routine managerial activities. The nation is divided between knowledge and ignorance. Human resources management plays a significant role in any organization. The main challenge in human resources management is capable and knowledgeable employee. Today it is a world of competition and day by day new policies are made and implemented in any business. Changes are inevitable in any organization. During the process of change every organization has to face resistance by the employees.Objective: The objective of study to check Impact of Nursing Manager Perception of Empowerment and Years of Experience on Resistance to Change in PracticeMaterial and methods: a descriptive correlational study was conducted to the impact of nursing manager perception of empowerment and years of experience on resistance to change in practice. The target population 150 and the study was conducted on head nurses of different hospitals. Participants were asked to fill demographic and conditions for work effectiveness questionnaire (CWEQ-II) and resistance to change scale. Conclusion: according to this study the perception of empowerment in nursing managers has significant relationship with resistance to change. As the perception of empowerment increases the degree of resistance decreases. In current health system, it is necessary to develop perception empowerment that has proven to effective to decrease resistance to change in practice among nurses.
\end{abstract}

Keywords: Nursing Manager, Empowerment, and Experience and Resistance to Change

DOI: $10.7176 / \mathrm{JHMN} / 62-11$

Publication date:May $31^{\text {st }} 2019$

\section{Introduction}

Now a days, the nation is divided between knowledge and ignorance. Human resources management plays a significant role in any organization. The main challenge in human resources management is capable and knowledgeable employee. Due to increased competition the managers do not have time to control their employee. The managers have to spend time to face various organizational challenges. The managers have to delegate the duties to the employee. The employees should have skills, capability and knowledge in this regard. Every professional is dynamic. The leaders of any organization cannot deal with the changing environment. The leader should encourage the employees to give ideas and participate in the organization matters. It enhances employ satisfaction and development of the organization (Read \& Laschinger, 2015).

Managerial empowerment, a lots of managerial techniques, knowledge, information, support, objective and goals which help in an organization increase allocation of powers and more independence is given to staff members to perform their jobs. The level of self-sufficient and decision-making influence on employees to perform their jobs.it also increases the organization's ability to assist communication between different units, giving decision makers at all levels access to the best information. It is responsibility of managers which have power to holding regular meetings to exchange information between managers and employees which increase employee access to information and required documents. Moreover, managers should encourage employees believe that they have the capacity to work. These beliefs create spirit of competence and developing a sense of self sufficient (Hasani \& Sheikhesmaeili, 2016).

Nurse Manager is defined as person who had twenty four hour accountability for managerial services. This position involved direct supervision of charge nurses on all shifts and other staff members. The importance of empowering to support practical environment of nurses who perceived ability to engage in professional practice behaviours that impact on perceptions of patient care quality and early career retention. Nurse Manager has improved abilities through effective communication skills, visibility, flexibility and collaborative behaviour which help to improve organization. Moreover, nurse manager also helps staff to give new ideas, innovation which also effect the efficiency in the favour of an organization (Morsiani, Bagnasco, \& Sasso, 2017).

Nurse Manager has the responsibility to solve work related problems. Job related problems should be solved by discussion, innovation, encouragement, corporation, work organization and intervention. However, nurse manager has many responsibilities related to job and managerial services. They also need peers support to solve various kind of problems related to ward management and administration. Which included dietician, therapists, physiotherapist and social workers, they are also support the nurse manager to solve problems of management (Laukkanen, Suhonen, \& Leino-Kilpi, 2016).

Nurse Managers play a vital role to maintain an organization. They are responsible for nursing employment, 
ward management and other routine managerial activities. Their presence is one of the reasons why most hospitals are functioning as smoothly as they should. On the other hand, Manager has also face many problems like inappropriate staffing, duty hours, funding restrictions, budgeting problems. A good manager should have objectives and techniques to solve problems and serve as role model to improve leadership style of nurse manager (Adriaenssens, Hamelink, \& Van Bogaert, 2017).

Empowerment of the staff is important concept in health department. The merits of empowered staff cannot be denied. It is beneficial for the hospital and as well as for the nurses. More Empowered nurses play a vital role in clinical teaching. It is therefore necessary to know how staff empowerment can improve the clinical environment (Kennedy, Hardiker, \& Staniland, 2015).

Changing environment help in growth and development. It is essential in gaining prosperity. Changes are often uninvited. It can happen anywhere in an organization, in home. In the modern world changes have become essential. Professionals are more exposed to change in working environment. One of reasons might be that people do not want to be change, they are motivated to resist (Spear, 2016).

An Organizational change management, in which manage the process of change within an organization. It is the responsibility of management's approach and strategy to take an organization through the alteration from today to a new future. Many factors influence on change process. These factors can either support or obstruct the change process. Success factors and complications are strongly related to each other. The reason is that one factor might be support a change in a certain situation, on the other hand this same factor can obstruct another change process in different situation. Therefore, it is more practical to talk about influencing factors on change process (Verhulst \& Lambrechts, 2015).

Some people are bored from same and stable daily routines. Which also increase the stress level and produce uncomfortable environment in an organization. People wants change because they have ability to adopt the change successfully, ambitious and have positive attitude towards change. A good manager should have new ideas, strategies and thoughts to help in betterment of an organization. On the other hand, some people have negative attitude towards the change because they do not want change, feel uncomfortable and consistent over time. Several strategies might be helpful to reduce existing factors like resistance to change contesting, avoidance, biased processing and empowerment. However, resistance to the change also depend on reasons like threat to freedom, namely and concern for deception. The people who are reluctant to change use empowerment and biased processing (Fransen, Smit, \& Verlegh, 2015).

Today it is a world of competition and day by day new policies are made and implemented in any business. Changes are inevitable in any organization. During the process of change every organization has to face resistance by the employees. Resistance to change may causes failure in the process of change which can harm organization development. Empowerment of staff can be beneficial for in the process of change management. Psychological empowered employees shows little resistance to change process (Goksoy, 2017). With the advancement in health industry. The nurses and managers are supposed to accept changes. It provides direction for further advancement in health and helps in better care of the patients (Nelson-Brantley \& Ford, 2017) in health and helps in better care of the patients (Nelson-Brantley \& Ford, 2017).

\section{AIMS OF THE STUDY}

The aim of this study was to assess the impact of nursing manager perception of empowerment and years of experience on resistance to change in practice

\section{LITERATURE REVIEW}

For the development and improvement of an organization, the role of the manager is very important to run smoothly an organization. A study was conducted on hospital management to explore the impact of leadership, years of experience and employee empowerment. The results of the study showed that self-management $(\mathrm{r}=0.626$, $\mathrm{p}=.000)$, work environment $(\mathrm{r}=.706, \mathrm{p}=.000)$, career advancement $(\mathrm{r}=.022, \mathrm{p}=.000)$ and leadership $(\mathrm{r}=.709, \mathrm{p}=$ $.000)$ have influence on an organizational effective outcomes and productive results. Hospital management should focus on facilitation of necessary resources, such as training information and other tools (Kruja, Ha, Drishti, \& Oelfke, 2016).

Empowerment is important tool for an organization. Managerial empowerment is also important factor which contribute and hold the process of effective management. A study was conducted on role of manager or supervision, empowering and enhancing the management practices in hospital nurses. The findings of the study revealed that psychological empowerment (mean $=3.60, \mathrm{SD}=0.73)$ and behavioural empowerment $($ mean $=3.44$, $\mathrm{SD}=.68$ ) have positive significant relation for managerial work and organization management. And also important for resistant to change (mean $=2.62, \mathrm{SD}=0.055)$ in health care practices. So organization should develop strategies to empower their subordinates and main representors of an organization to enhancing the abilities of effective manager in nursing staff to show less resistance to change (Montani, Courcy, Giorgi, \& Boilard, 2015).

Experience is more important for effective managerial work. A study was conducted on teachers to check the 
relationship of experience and empowerment showed there is no difference on perception of empowerment of new and old. Experience do not create any difference on the perception of empowerment in teachers (Baleghizadeh \& Goldouz, 2016).

A study conducted to check the relationship of structural empowerment, psychological empowerment and work engagement in nurses. The empowerment and work engagement plays a main role in retention of health care providers in clinical nurses. The results showed that structural empowerment and psychological empowerment perception is interconnected and have positive relationship between structural and psychological empowerment (DiNapoli, O’Flaherty, Musil, Clavelle, \& Fitzpatrick, 2016).

Change is alteration in an organizational policies and procedures. But some people or employees did not like the change. They have negative views about the change polices. Because they did not want change and even not accepted. So, a study was conducted on resistance to change characteristics and motivation for work force in health care setting. The results of the study indicated that resistance to change (mean $=2.43, \mathrm{SD}=0.54)$, leadership (mean= $3.80, \mathrm{SD}=0.62)$, participation (mean $=2.18, \mathrm{SD}=0.91)$, justice $($ mean $=3.75, \mathrm{SD}=0.68)$ and informational justice (mean=3.33, $\mathrm{SD}=0.77$ ). Which showed that informational justice has relationship between resistance to change (Georgalis, Samaratunge, Kimberley, \& Lu, 2015).

Nursing. Although the predictable value of communication skills to nursing, research designate that many nurses not have the skills to communicate caringly and visibly with patients (Ferreira ${ }^{\mathrm{a}}$ et al., 2016).

\section{METHODOLOGY}

SETTING

The research was conducted in government hospitals.

\section{RESEARCH DESIGN}

Descriptive correlational design was used in this study

\section{POPULATION}

Head nurse of government hospitals.

\section{SAMPLING}

Convenient sampling was use in this study

\section{DATA GATHERING PROCEDURE}

A formal written letter of permission to conduct the research. And questionnaire was distributed in head nurses.

\section{ANALYZE DATA}

- Data was analysed through Statistical Package for the social science (SPSS) 25 versions.

- The correct and suitable analysis of research result is ensuring data reliability.

\section{STUDY TIMELINE}

The study was conducted from February 2019 to May 2019.

Sample Size:

Sample size will 129 based on the number of head nurses who are doing job the in Jinnah Hospital Lahore and Lahore General hospital.

Sample size is 129 according to Slovene's formula (Parveen, Hussain, Majeed, Afzal, \& Gilani, 2018).

Total population $=190$

$95 \%$ confidence

$5 \%$ error $5 / 100=0.05$

If $\mathrm{N}=190 \quad \mathrm{n}=$ sample size

$\mathrm{E}=$ margin of error

$\mathrm{n}=\mathrm{N} /[1+(\mathrm{N})(\mathrm{E}) 2]$

$\mathrm{n}=190 /[1+190(0.05) 2]$

$\mathrm{n}=190 /[1+190(0.0025)]$

$\mathrm{n}=190 /[1+0.475]$

$\mathrm{n}=190 / 1.475$

$\mathrm{n}=129$ (approx.)

Inclusion Criteria:

Following head nurses in Jinnah hospital Lahore will included in data collection:

- Those who was present at the time of data collection.

- Those who was willing to participate. 
- Only supervisor/ nurse manager/ head nurse/ nursing superintendents was participated.

Exclusion Criteria:

Following students from school of nursing in Jinnah hospital Lahore will be not included in data collection:

- Those who were not present at the time of data collection.

- Those who were not willing to participate.

- Charge nurses was not participated

\section{DATA COLLECTION PROCEDURE}

At first informed consent will be taken from all participants. It was introduce in writing to the head of hospital. Participants will be asked to fill demographic and conditions for work effectiveness questionnaire (CWEQ-II) and resistance to change scale. The demographics consist of five demographic questions experience, Period in current role, age, highest degree attained in nursing, and current position title. Conditions for work effectiveness questionnaire (CWEQ-II) consist of six sub titles access to opportunity, access to resources, access to information, access to support, formal power an informal power. Based on the Likert scale, each item was scored from 1 to 5 with higher scores showing better perception of empowerment. Resistance to change scale consist of seventeen questions and is based on the Likert scale, each item was scored from 1 to 6 with higher scores showing resistance to change (Burgess, 2014).

Kantar's theory of structural empowerment will be incorporated in which organizational behaviour and empowerment is included. This theory is closely related to my research article which is on impact of manager perception of empowerment and year of experience on resistance to change.

According to my research point of view, empowerment is promoted in work environments that provide employees with access to information, resources, support, and the opportunity to learn and develop organizational commitment. An organization are functioning as smoothly as they should, the role of nurse manager is very important. A good manager should have objectives and techniques to solve problems and serve as role model to improve leadership style of nurse manager. Moreover, organizational change is help to reduce daily boring routines, workload and work policies and procedures. But some people or subordinates have negative views about change. Therefore, nurse manager experience and empowerment which come in different forms like behavioural and psychological, may help to overcome resistance to change. My research will also help the managers or supervisors to develop strategies to reduce resistance to change (Burgess, 2014).

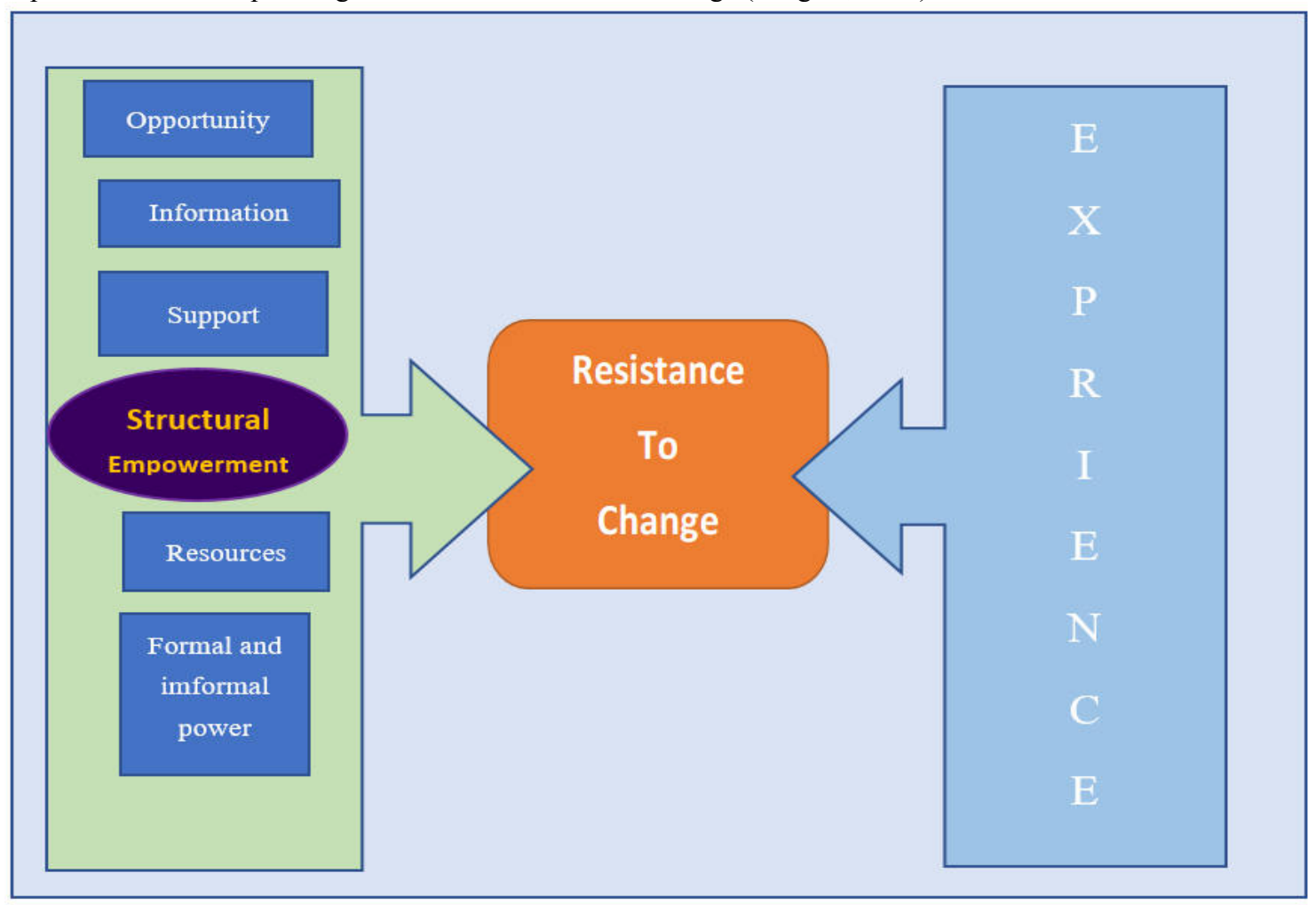


Results

This section presents the outcomes of the study.

PROFILE OF THE RESPONDENTS

Respondents were taken from government hospitals of Lahore

Research Question- Relationship of Nursing Manager Perception of Empowerment and Years of Experience on Resistance to Change in Practice

Table 1 shows the demographic data for the participants of this study conducted in public hospitals of Lahore.

\section{Variables}

How long have you been in management?

How long have you been in your current role?

How old are you?

$$
\text { Highest Degree }
$$$$
\text { Earned }
$$

Current Position

Responses
0-5 years
6-10 years
0-5 years
6-10 years
40-50 years
50-60 years
BNS/specialty
ing superintendent
supervisor

Ward sister

$\mathbf{N}$
122
7
124
5
34
95

129

5

34

$$
\begin{gathered}
\% \\
94.6 \\
\\
5.4 \\
96.1 \\
\\
3.9 \\
26.4 \\
73.6
\end{gathered}
$$

100

$\begin{array}{cc}1 & 0.8 \\ 3 & 2.3 \\ 125 & 96.9\end{array}$

1.03880

0.19377

2.7

0.44228

2.0

SD

0.22742

\author{
0.00
}

$4.9302 \quad 0.39894$

2.3

This sample of respondents, all the nursing managers were females (100\%). Among the sample 122 nursing manager had 0 to 5 years of experience $(94.6 \%), 7$ participants had 6 to 10 years of experience $(5.4 \%)$.

In this study124 nursing managers had 0 to 5 years in this role of management (96.1\%), 5 participants had 6 to 10 years o $(3.9 \%)$. The participants of the study were participants in 34 participants belong to 40 to 50 years age group $(26 \%)$ and 95 were in 50 to 60 years age group $(96.9 \%)$. The demographic data shows in Table 1 that all the respondents were nursing managers, mostly female, in management role, and educated in nursing.

The table no3. shows normal distribution of resistance to change scale scores. The mean value was 48.04 and standard deviation 23.83. The skewness of the Resistance to change scale scores was 0.448 . This illustrates that the Pearson's correlation can be used to check the relationship of nurse manager perception of empowerment and resistance to change scale can use.

Correlation Analysis

Table 2

\begin{tabular}{|c|l|l|}
\hline Sr\# & Parameter & Values \\
\hline 1. & Mean & 70.89 \\
\hline 2. & Std. Deviation & 24.80 \\
\hline 3. & Skewness & 0.291 \\
\hline
\end{tabular}

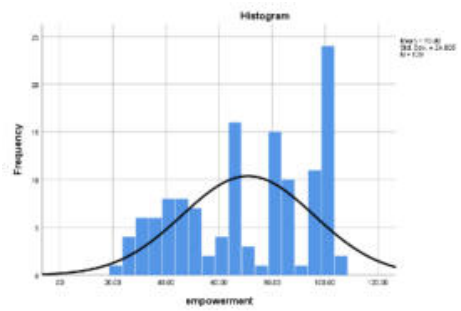

Table 3

Figure.1

\begin{tabular}{|c|l|c|}
\hline \multicolumn{1}{|l|}{ Sr\# } & parameter & Values \\
\hline 1. & mean & 48.04 \\
\hline 2. & Std. Deviation & 23.83 \\
\hline 3. & Skewness & .448 \\
\hline
\end{tabular}

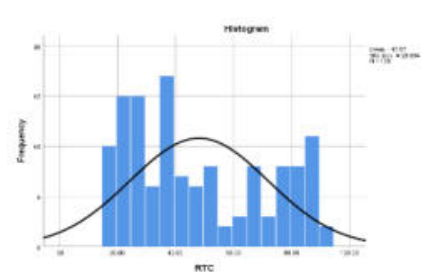

Figure 2 
Table 4

\begin{tabular}{|c|l|l|l|}
\hline Sr.no & Questionnaire & Cronbach alpha & Items \\
\hline 1. & Empowerment & 0.994 & 21 \\
\hline 2. & Resistance to change & 0.992 & 17 \\
\hline
\end{tabular}

This portion of the study provides data used to check the nurse managers perception of empowerment. The conditions of work effectiveness scores had a mean of 70.90 and Standard deviation of 24.805 which indicated that the respondents had strong perception of empowerment in the hospital. As shown in Figure 1, the distribution for the CWEQ-II scores was normal; the skewness of the scores was low at 0.291. Which indicates that multiple linear regression and Pearson's coefficient were appropriate for testing the relationship between empowerment, years of experience and resistance to change in practice.

The table no. 4 shows the reliability scales used for measure of internal consistency of the research instrument. If the Cronbach alpha shows the validity of the questionnaire.

Table .5 Correlation Analysis

\begin{tabular}{|c|c|c|}
\hline $\mathrm{N}=117$ & $\mathrm{R}$ & $\mathrm{P}$ \\
\hline $\begin{array}{l}\text { Correlation between perception of empowerment in nurse manager with resistance to } \\
\text { change in practice }\end{array}$ & -0.355 & .000 \\
\hline Correlation between experience and resistance to change in practice & -.232 & .008 \\
\hline
\end{tabular}

On the basis of normal distribution of the data bivariate correlation was chosen to check the relationship of the Perception of Empowerment and Resistance of change scale. The above table shows the bivariate correlation of the Perception of Empowerment and Resistance of change scale. The analysis of correlations between the independent and dependent variables illustrated that there a significant relationship perceptions of empowerment and resistance to change in practice.

The above table shows that $129(\mathrm{n}=129)$ nursing managers were surveyed and Pearson $\mathrm{r}$ data revealed negative correlation $(r=-3.55)$. The nurse managers who have more concept of empowerment show less resistance to changes in practice. The negative value of the $r(r=-3.55)$

Coefficient indicated that the perceptions of empowerment in nurse managers and RTC move in opposite directions. As the perceptions of empowerment increases in nurse managers the degree. Additionally, there was significant association between experience of the nurse managers and resistance to change in practice. The above table shows that $129(\mathrm{n}=129)$ nursing managers were surveyed and Pearson $\mathrm{r}$ data revealed negative correlation $(\mathrm{r}=-232)$. The nurse managers who have more experience show less resistance to changes in practice. The negative value of the $r(r=-232)$

Coefficient indicated that the perceptions of empowerment in nurse managers and RTC move in opposite directions. As the experience increases in nurse managers the degree of resistance decreases.

\section{Discussion}

The purpose of the current study was to check the relationship between nurse manager perception of empowerment, experience and resistance to change. I used Pearson's coefficient and multiple linear regression analysis to test for the existence of a relationship between the variables of empowerment, years of experience, and resistance to change among health care managers. Testing for these assumptions showed no apparent violations. The correlation results showed there was an association between concept of empowerment and resistance to change among nurse managers working in government hospital of Lahore. The negative values $(r=-0.355, p \leq .05)$ shows that empowerment and resistance to change has negative relationship. The experience and resistance to change has also a negative relationship $(\mathrm{r}=-0.232)$

After analyzation of the results, I rejected this study's first null hypothesis (H10; no relationship existed between the nurse managers' perception of empowerment and degree of resistance to change. Kanter formulated managers with perceptions of powerlessness would resist change and Kotter (1996) proposed that empowerment is a key requirement for managers to effect change. Kanter and Kotter's positions on power and change resistance indicated a relationship between empowerment and change resistance exists; as shown by these results, such a relationship exists among the participants of this study.

\section{CONCLUSION}

The present study examined the relationship of empowerment, managerial experience and resistance to change in practice in nurse managers in government hospitals of Lahore. The nurse managers who have more perception of empowerment shows less resistance to change. Experience also causes decrease in resistance to change.

The correlation between perception of empowerment and resistance to change was $r=-0.355(p<0.05)$ which showed that there is a significant negative correlation between the perception of empowerment and resistance to change in nurse managers. The experience also decreases the degree of resistance in nurse managers. 


\section{Recommendations:}

The same study could be conducted with a large sample size and more than two hospitals to generalize the results. The study can be conducted in different setting with similar instruments and variables.

An experimental and control group study can be done to identify the difference between empowerment and resistance to change similar settings.

Further study to measure the perception of empowerment and resistance to change in nurse managers would allow for the relationship between perception of empowerment, experience and resistance to change

\section{LIMITATIONS}

The sample was only 129 nurse manager, so the results of the study could not be generalized on other clinical settings.

The sample used for this study, which were belongs to only government institutes. Participants could not be closely observed in data collection and which could be assuring to the data validity.

In this study, there was no evidence presented on preceptor nursing experience and preceptor preparation which could develop professional skills in nursing students.

\section{ACKNOWLEDGEMENT}

I would like to thank the following people who in many ways contributed to this piece of work. First and foremost, I would like to thank Mr. Muhammad Afzal (The Principal of Lahore School of Nursing) who allowed me to do this study and guided me. I would thank to Sir Muhammad Hussain for being my preceptor and for being the greatest inspiration for my work when I had no idea to perform a research work. I am indebted to her and I admire the way in which she explained very difficult concepts in very simple ways. She is very helpful in giving me suggestions. I would like to say special thanks to Mst. Rita Burgess, who granted me permission of using her research instrument. I would also like to thank all the participants and my colleagues. Their participation made this study possible. It is a great pleasure to have all of these wonderful people in my life. I thank the management of University of Lahore.

\section{References}

Adriaenssens, J., Hamelink, A., \& Van Bogaert, P. (2017). Predictors of occupational stress and well-being in FirstLine Nurse Managers: A cross-sectional survey study. International journal of nursing studies, 73, 85-92.

Baleghizadeh, S., \& Goldouz, E. (2016). The relationship between Iranian EFL teachers' collective efficacy beliefs, teaching experience and perception of teacher empowerment. Cogent Education, 3(1), 1223262.

Burgess, R. E. (2014). A correlational analysis of empowerment and experience with resistance to change.

DiNapoli, J. M., O’Flaherty, D., Musil, C., Clavelle, J. T., \& Fitzpatrick, J. J. (2016). The relationship of clinical nurses' perceptions of structural and psychological empowerment and engagement on their unit. Journal of Nursing Administration, 46(2), 95-100.

Fransen, M. L., Smit, E. G., \& Verlegh, P. W. (2015). Strategies and motives for resistance to persuasion: an integrative framework. Frontiers in psychology, 6, 1201.

Geldhof, G. J., Preacher, K. J., \& Zyphur, M. J. (2014). Reliability estimation in a multilevel confirmatory factor analysis framework. Psychological methods, 19(1), 72.

Georgalis, J., Samaratunge, R., Kimberley, N., \& Lu, Y. (2015). Change process characteristics and resistance to organisational change: The role of employee perceptions of justice. Australian Journal of Management, 40(1), 89-113.

Goksoy, A. (2017). The Role of Psychological Empowerment and Organizational Citizenship Behaviors on Employee Resistance to Change. European Journal of Interdisciplinary Studies, 3(2), 85-93.

Hasani, K., \& Sheikhesmaeili, S. (2016). Knowledge management and employee empowerment: A study of higher education institutions. Kybernetes, 45(2), 337-355.

Kennedy, S., Hardiker, N., \& Staniland, K. (2015). Empowerment an essential ingredient in the clinical environment: A review of the literature. Nurse education today, 35(3), 487-492.

Kruja, D., Ha, H., Drishti, E., \& Oelfke, T. (2016). Empowerment in the hospitality industry in the United States. Journal of Hospitality Marketing \& Management, 25(1), 25-48.

Laukkanen, L., Suhonen, R., \& Leino-Kilpi, H. (2016). Solving work-related ethical problems: The activities of nurse managers. Nursing ethics, 23(8), 838-850.

Montani, F., Courcy, F., Giorgi, G., \& Boilard, A. (2015). Enhancing nurses' empowerment: the role of supervisors' empowering management practices. Journal of advanced nursing, 71(9), 2129-2141.

Morsiani, G., Bagnasco, A., \& Sasso, L. (2017). How staff nurses perceive the impact of nurse managers' leadership style in terms of job satisfaction: a mixed method study. Journal of nursing management, 25(2), 119-128.

Nelson-Brantley, H. V., \& Ford, D. J. (2017). Leading change: a concept analysis. Journal of Advanced Nursing, 
73(4), 834-846.

Parveen, R., Hussain, M., Majeed, I., Afzal, M., \& Gilani, S. A. (2018). Influence of Poverty on Moral Development in Rural Community Lahore. International Journal of Social Sciences and Management, 5(3), 113-124.

Read, E. A., \& Laschinger, H. K. (2015). The influence of authentic leadership and empowerment on nurses' relational social capital, mental health and job satisfaction over the first year of practice. Journal of Advanced Nursing, 71(7), 1611-1623.

Spear, M. (2016). How to facilitate change. Plastic Surgical Nursing, 36(2), 58-61.

Verhulst, E., \& Lambrechts, W. (2015). Fostering the incorporation of sustainable development in higher education. Lessons learned from a change management perspective. Journal of Cleaner Production, 106, 189-204.

Wilson, D. R. (2018). The healthcare manager's perception of empowerment: The discovery. AAYAM: AKGIM Journal of Management, 8(1), 17-20. 